\title{
Motivation for Cessation of Smoking and Its Associated Factors Among Patients Who Smoke Admitted to A Tertiary Hospital in North Kerala
}

\author{
Usha Karunakaran”, Binoo Divakaran, Suma Harindramohan, Ganesh Mallar, \\ Jayasree Anandabhavan Kumaran
}

Department of Community Medicine, Academy of Medical Sciences, Pariyaram, Kannur, India

\section{Email address:}

ushavenglat@yahoo.co.in (U. Karunakaran), binoovimal@gmail.com (B. Divakaran), sumaharindra@gmail.com (S. Harindramohan), ganeshbmallar@gmail.com (G. Mallar), akjayasree@gmail.com (J. A. Kumaran)

${ }^{*}$ Corresponding author

To cite this article:

Usha Karunakaran, Binoo Divakaran, Suma Harin dramohan, Ganesh Mallar, Jayasree Anandabhavan Kumaran. Motivation for Cessation of Smoking and Its Associated Factors Among Patients Who Smoke Admitted to A Tertiary Hospital in North Kerala. Science Journal of Public Health. Vol. 5, No. 1, 2017, pp. 35-40. doi: 10.11648/j.sjph.20170501.15

Received: November 21, 2016; Accepted: December 6, 2016; Published: January 12, 2017

\begin{abstract}
Use of tobacco is associated with significant morbidity and mortality globally. It is one of the leading risk factors of several diseases including cardiovascular pulmonary diseases and cancers. Stopping smoking has immediate and major health benefits. A major opportunity to promote health and well being exists in hospitals when smokers get admitted as patients. Doctors and paramedical staff have the authoritative power to ask patients to stop smoking. Thus this study was conducted to find out the percentage of smoker patients who were motivated by doctors to quit smoking. In addition the socio demographic characteristics and smoking habits were studied and also factors that were associated with attitude for quitting smoking were assessed. A hospital based cross sectional study with quantitative method of data collection was done among patients who are smokers admitted to this hospital for smoking related diseases like coronary vascular disease (CVD), lung and any other diseases apparently not related to smoking. Quantitative data was collected through face to face interview using a pre tested questionnaire. Analysis was done with descriptive statistics and chi square using epi info. Out of 179 patients who participated 177 were males. The mean age of patients was 54.8 with a standard deviation of 14.6 years. More than $85 \%$ belonged to the lower and lower middle class. More than $50 \%$ of patients smoked cigarettes. The mean age of initiation of smoking was 16 years and peer pressure was the most common reason for initiation. In this study $64 \%$ of the total smoker patients were motivated by doctors to quit smoking while only $26 \%$ of smoker patients admitted for non related diseases were motivated by doctors Brief advice by doctors and the smoking related diseases namely lung and CVD's were factors associated with motivation to stop smoking while social class was not associated with motivation for cessation. Simply addressing the topic of smoking is a crucial first step in a medical consultation. Patients with tobacco-related complaints should be told that their problem is related to tobacco use and they should consider quitting. With patients who do not have tobacco related diseases the subject of tobacco usage will have to be addressed in a general way. Introducing the smoking topic can initiate a structured intervention tailored to the patient's needs.
\end{abstract}

Keywords: Smoking, Cessation, Motivation

\section{Introduction}

Use of tobacco is associated with significant morbidity and mortality globally. [1] The tobacco epidemic is one of the fastest growing epidemics in the world. It is well documented that smoking remains one of the leading risk factors of several diseases including cancers, cardiovascular diseases and pulmonary diseases and also deaths in India. [2]

More than one third of India's population (275 million people) was estimated to be tobacco users and 1 million deaths a year was attributed to smoking in 2010 [3, 4]

The total number of tobacco users is expected to rise to 1.6 
billion by 2020 globally. At present tobacco use causes death of 6 million people globally. [4] This is expected to rise to 10 million by 2020 out of which developing countries would have an around estimated death of 7 million because of the increasing use of tobacco $[4,5,6]$

Stopping smoking has major and immediate health benefits. Former smokers live longer than continuing smokers. Health benefits are seen even in the elderly people who are in the age of 70 to 74 years at the time they stop smoking. Risk reduction on smoking cessation is seen in all diseases. In coronary heart disease risk drops to $50 \%$ at one year of stopping smoking and becomes non smoker rates at 10 years. In lung cancer risk drops to less than $60 \%$ at one year of stopping smoking and attains non smoker rates at 10 years. [7]

Helping people to stop smoking is a key step in reducing the impact of the tobacco epidemic and improving population health.

There are several proven measures to reduce the overall consumption of tobacco. Some of these are raising taxes, smoke free laws, public awareness, alternate cropping and banning advertising. [5, 8]

A major opportunity to promote health and well being by encouraging smokers to stop smoking exists when smokers become hospital patients. Physicians and other paramedical staff play a unique and important role in motivating patients to achieve behavior changes necessary in managing several diseases. Doctors and nurses have the authoritative power and are regarded as reliable and knowledgeable sources of health information. Though some clinicians believe they do not have the time to provide advice, motivation to stop smoking takes as little time as 3 minutes. All patients should be asked about their smoking status and smokers routinely advised to quit. Patients who receive clinician assistance are more likely to quit smoking successfully than patients who try on their own.[7, 8] There are several randomized controlled trials that indicate that even brief advice by physicians increase quit rates among smokers. [9]

By doing this study we wanted to know what percentage of smoker patients were motivated by doctors to stop smoking. In addition we wanted to assess impact of advice on the smoking cessation attitude of these patients. We also wanted to know whether the disease they were suffering from was a factor that led to smoking cessation and whether social class had a bearing on smoking cessation.

\section{Methods and Materials}

\subsection{Study Design and Setting}

A hospital based cross sectional study with quantitative method of data collection, was conducted in Academy of Medical sciences, a medical college situated in Kannur district of Kerala, a state situated in South India. The study was conducted from August $1^{\text {st }} 2010$ to January $31^{\text {st }} 2011$.

\subsection{Study Population}

The study population was all patients aged 15 years and above who were smokers, admitted to this hospital.

\subsection{Sample Size}

The sample size was computed using Fischer's (1998) formula $\left(n=Z^{2} p q / d^{2}\right)$, where

$\mathrm{n}=$ Sample size

$\mathrm{Z}=1.96$, that is the value of normal standard deviate corresponding to $95 \%$ confidence level

$\mathrm{p}=36$ (36\% smoking prevalence in India in $2000-\mathrm{WHO})$. [10]

$$
\mathrm{q}=100-\mathrm{p}=64
$$

$\mathrm{d}=7.2$ ( $20 \%$ error margin of prevalence).

Therefore the desired sample size was calculated as follows: $=1.96^{2} \times 36 \times 64 / 7.2^{2}$

$$
=170
$$

A total of 179 patients were obtained during our study period.

\subsection{Method of Data Collection}

Quantitative data was collected through face to face interview using a pre tested questionnaire. The questionnaire was prepared in English after reviewing literature. It was then translated into local language, Malayalam, and back translated into English to check for inconsistencies. A pilot testing was done among 10 smoker patients and corrections made accordingly. The data collectors were junior residents who were able to communicate in local language. Training was given to the data collectors by the investigators to help them become familiar with data collection instrument. After data collection brief advice regarding benefits of stopping smoking was given to patients and their willingness to quit smoking was assessed.

\subsection{Variables}

\subsubsection{Dependent Variable}

Motivation for stopping smoking

\subsubsection{Independent Variable}

- Type of disease person suffering from: The diseases were classified as those which are related to smoking and those which are apparently not related to smoking.

- Social class of patients: This was classified as patients belonging to upper class, middle class or lower class based on education, occupation and income.

- Motivators for stopping smoking: Persons in the hospital setting who motivated the patients to stop smoking at the time of admission.

\subsection{Operational Definitions [11, 12, 13]}

Cigarette - Consist of shredded or reconstituted tobacco, processed with hundreds of chemicals, wrapped in paper, and often with a filter and manufactured by a machine. They are the predominant form of tobacco used worldwide.

Bidi-Consist of a small amount of tobacco, hand-wrapped in dried temburni leaf and tied with string. Despite their small size, their tar and carbon monoxide deliveries can be higher than manufactured cigarettes because of the need to puff harder to keep bidis lit. Bidis are used extensively in 
areas of Southeast Asia and are the most commonly smoked tobacco product in India.

Smoking initiation - Whether or not the person reports having "ever tried cigarette smoking, even one or two puffs

Smoker - Someone who, at the time of the survey, smokes any tobacco product either daily or occasionally or an adult who has smoked 100 cigarettes in his or her lifetime and who currently smokes cigarettes. In this study a smoker was defined as one who smoked daily or occasionally till admission to this hospital.

Heavy smoker -Defined as a person who smokes more than 25 cigarettes per day.

Quit attempt: Quantitatively defined as having stopped smoking for one day or longer with the intention of quitting.

\subsection{Statistical Analysis}

Descriptive statistics like mean, standard deviation, frequencies and percentages were used and inferential statistics like chi square was used. A p value less than 0.05 was taken to be significant. Epi info version 7.0 was used for statistical analysis.

\subsection{Ethical Considerations}

Institutional ethical committee clearance was obtained.

\section{Results}

Between August 2010 and January 2011, 179 patients admitted to this hospital for various diseases were identified as smokers and included in this study.

\subsection{Socio Demographic Characteristics}

The mean age of the patients was 54.8 years with a standard deviation of 14.6 years. Out of the 179 respondents $177(98.9 \%)$ were males.

Table 1. Age distribution of the respondents.

\begin{tabular}{lll}
\hline Age & Number & Percent \\
\hline $21-30$ & 8 & 4.5 \\
$31-40$ & 24 & 13.4 \\
$41-50$ & 45 & 25.1 \\
$51-60$ & 48 & 26.8 \\
$61-70$ & 27 & 15.1 \\
$71-80$ & 19 & 10.6 \\
$81-90$ & 8 & 4.5 \\
\hline
\end{tabular}

From table 1 it is evident that there was an increase in the number of smokers up to 55 years of age and then the numbers declined. This is in accordance to prevalence studies on smoking done in India and other developed countries [14, 15]

Table 2. Educational level of the patients who smoked.

\begin{tabular}{|c|c|c|}
\hline Education & No. & Percent \\
\hline Illiterate & 3 & 1.7 \\
\hline Primary & 51 & 28.5 \\
\hline High School & 68 & 38 \\
\hline $\begin{array}{l}\text { Secondary/ } \\
\text { diploma }\end{array}$ & 49 & 27.4 \\
\hline Degree/PG & 6 & 3.4 \\
\hline Professional & 2 & 1 \\
\hline
\end{tabular}

Table 2 shows that majority of the study group had education up to high school and also $1.7 \%$ of them were illiterate.

Table 3. Occupation status of the respondents.

\begin{tabular}{lll}
\hline Occupation & No. & \% \\
\hline Unemployed & 7 & 4 \\
Unskilled & 113 & 63 \\
Semiskilled & 33 & 18.4 \\
skilled & 12 & 6.7 \\
Clerical/farmer/ & 8 & 4.5 \\
shop owner & & \\
Semiprofessional & 4 & 2.2 \\
Professional & 2 & 1.1 \\
\hline
\end{tabular}

From Table 3 above, it is seen that unskilled laborers formed the major part (63\%) of the study group.

Table 4. Monthly income of the respondents.

\begin{tabular}{lll}
\hline Monthly income(Rs.) & No. & \% \\
\hline$\leq 10000$ & 153 & 85.5 \\
$10001-20000$ & 17 & 9.5 \\
$20001-50000$ & 9 & 5 \\
\hline
\end{tabular}

We used the modified Kuppuswamy scale 2009 for assessing the socio economic status. [16] We recategorised the income range according to information obtained. Most of the respondents belong to the lower middle class and lower class $(153,85.5 \%), 24(13.4 \%)$, belonged to the upper middle class and $2(1.1 \%)$ belonged to the upper class. Various studies also show that smoking prevalence is more among the lower socioeconomic class and the less educated people. [14, $15,17]$

\subsection{Smoking Habits of the Study Population}

Table 5. Type of Smoking Among the Respondents.

\begin{tabular}{lll}
\hline Type of smoking & No & \% \\
\hline Bidi & 62 & 34.6 \\
Cigarette & 100 & 55.9 \\
Bidi and Cigarette & 17 & 9.5 \\
\hline
\end{tabular}

According to GATS India fact sheet 2009 - 2010 [18] there are more bidi smokers than cigarette smokers in India. In our study population we had more cigarette smokers than bidi smokers. (Table 5) 
Table 6. Reasons to initiate smoking among the study population.

\begin{tabular}{lll}
\hline Reasons to start smoking & No. & \% \\
Peer Pressure & 114 & 63.6 \\
Fun & 22 & 12.1 \\
Father smoking & 39 & 22.3 \\
Easy Availability & 4 & 2 \\
\hline
\end{tabular}

From Table 6, it is seen that peer pressure was the major reason $(63.6 \%)$ for initiation to smoking. Surrounding influence, stress and fun were reasons for initiation in a study done by Chezhian et al in Chennai. [19] Other studies done show determinants of smoking initiation as peers influence, parents influence, social tool, coping tool and curiosity [13, 20]

Out of the 179 patients $92(51.6 \%)$ were admitted to the hospital for lung and heart disease while 87 (48.4\%) were admitted for diseases other than lung and CVD.

The mean age of starting smoking was 16 years. Various studies show that smoking initiation in India varies between 13 to 20 years of age. [18, 19, 21]

The mean duration of smoking among those with CVD was 35 years while it was 22 years for those with other non related diseases.

About $83 \%$ (148) were heavy smokers, smoking 3 or more packets per day.

Out of these 179 patients who smoked 103 (58\%) consumed alcohol and $16(9 \%)$ chewed tobacco. Several studies show a strong correlation between dose and pack/years and onset of lung and heart diseases [22-24]

Prior to hospital admission 6 patients from the CVD and lung disease group and 6 patients from the other diseases group had stopped smoking but restarted the habit.

Table 7. Reasons to restart smoking

\begin{tabular}{lll}
\hline Reasons to restart smoking & No. & \% \\
\hline No energy to work & 4 & 33.3 \\
Peer pressure & 3 & 25 \\
Stress & 5 & 41.7 \\
\hline
\end{tabular}

Table 7. shows that stress was the most common reason $(41.7 \%)$ to restart smoking. Other studiesmore or less show the same reasons for restarting smoking. [25]

\subsection{Motivation for Cessation at Time of Admission}

Table 8. People who motivated patients to stop smoking at time of admission.

\begin{tabular}{lll}
\hline Motivators for patients with heart and lung disease & No & \% \\
\hline Doctors & 59 & 64.2 \\
Nurses & 18 & 19.8 \\
Family members & 15 & 9.9 \\
Motivators for patients with other diseases & No. & $\%$ \\
Doctors & 23 & 26.3 \\
Nurses & 7 & 7.9 \\
Family members & 8 & 9.2 \\
None & 49 & 56.5 \\
\hline
\end{tabular}

Table 6 above shows that $64 \%$ of smokers with CVD and lung disease received advice to quit smoking while $26 \%$ of smokers with non related disease received advice. This difference in levels of motivation between both the groups was significant $(\chi 2=75.37, \mathrm{p}<0.05)$.

There are studies which show that doctors identify only $56 \%$ of smokers and only $22 \%$ received advice to quit smoking. [26]

Doctors more often motivated patients with CVD and lung disease to quit smoking. There are studies which show that patients with lung and heart disease are more often screened for smoking habits and therefore advised to quit. [27]

\subsection{Factors Associated with Smoking Cessation Motivation}

Among those patients who had CVD and lung disease 70 had stopped smoking and 22 had not stopped during the hospital stay and among those with other diseases only 8 had stopped smoking and 79 had not stopped smoking. This difference was significant $(\chi 2=81.37, \mathrm{p}<0.05)$. Patients with smoking related disease made an attempt to quit more than the patients with non smoking related diseases.

We considered socio economic class as a factor which motivated smoking cessation. It was seen that 65 patients in the low and lower middle social class had stopped smoking while 88 had not and 14 in the upper middle and upper class had stopped smoking while 12 had not. The difference was not significant. $(\chi 2=1.163, \mathrm{p}=0.28)$. Social class did not play a role in smoking cessation motivation.

The junior residents after the interview briefly advised the patients about benefits of stopping smoking. Out of the 179 patients, $152(84.8 \%)$ were willing to attend counseling sessions or accept pharmacological means to enable them to completely quit the tobacco smoking habit, they comprised of 86 in the CVD and lung disease group and 66 in the other diseases group.

Table 9. Association of type of disease with willingness to attend counseling sessions.

\begin{tabular}{lll}
\hline Type of disease & $\begin{array}{l}\text { Willing to attempt } \\
\text { quitting }\end{array}$ & $\begin{array}{l}\text { Not willing to } \\
\text { attempt quitting }\end{array}$ \\
\hline CVD and lung disease & 86 & 6 \\
Other diseases & 66 & 21 \\
\hline
\end{tabular}

There was a significant association between the type of disease and willingness to make a quit attempt following advice from doctors, $\left(\chi^{2}-10.83, \mathrm{p} \leq 0.05\right)$.

Thus in this study which comprised of mainly male smoking patients who belonged to the lower class and lower middle class, it was seen that treating doctors more often advised patients with CVD and lung disease to quit smoking. Tobacco related disease and brief advice by doctors were factors which motivated patients to make an attempt to stop smoking permanently, while social class did not play a role in motivating patients to stop smoking.

\section{Discussion}

About 30 - 40\% of current smokers attempt to quit each year and $2 \%$ to $6 \%$ are successful. Most smokers make multiple attempts, such that half eventually quit smoking.

Though there are clinicians who do not believe brief 
advice is effective, several randomized trials indicate that even brief advice increases quit rates. On the other hand there are clinicians who believe they don't have the time to provide advice. However, the major role clinicians' play is to motivate smokers to quit, which can take as little as 3 minutes. [8] This is also a cost effective method. Some clinicians fear that the situation is embarrassing, however, exit polls show that most smokers rate doctors who do not ask about their smoking habits as less competent doctors.[9]

A major gap remains between knowledge of smoking risks and its translation into clinical practice even in countries where doctors' knowledge of the risks of smoking is good. Though doctors claim to ask and advise about smoking, only a minority of smoking patients recall being advised by their doctors. Therefore it is clear that rates of smoking detection and offer of advice are not optimal and that doctors tend to overestimate these rates compared with medical record audits and patient self-reports. [7]

Smokers who are advised by their doctor to stop smoking are nearly twice as likely to do so as those who are not [7]

Though role of giving advice by doctors to patients to stop smoking has improved over the years, this role is yet to attain its full potential.

All patients should be asked about their smoking status and smokers routinely advised to quit.

There are a number of reasons why clinicians can be effective in helping people stop smoking.

A high proportion of the population has easy access to doctors at the primary care level.

Doctors and nurses are regarded as reliable and knowledgeable sources of health information. In addition, persons are more vulnerable while in a hospital where doctors and staff nurses are more authoritative and therefore more willing to accept health risk counseling. When direct negative consequences of smoking are present or are visible, patients tend to be even more receptive to advice about stopping smoking. Studies have shown that the majority of smokers who want help to stop smoking prefer to seek it from a health professional, rather than using self-help approaches. [7]

Most medical practitioners see their job as not only treating disease, but also as a health adviser to patients. [27] Therefore interventions to stop tobacco use should be strategically used in the same way as vaccination; they should be offered to every person. Doctors should routinely ask all patients over 15 years of age about smoking and tobacco use during each visit, provide advice about stopping to those who smoke, and help patients to stop when they are ready.

\section{Conclusion}

Seventy five to $80 \%$ of smokers want to quit smoking, one third make a serious attempt, but only $1-2 \%$ stop. Seventy percent of smokers visit a physician each year. Only $15 \%$ are offered some form of assistance. [28]

Brief intervention strategies used by physicians to assist smokers in quitting can lead to cessation rates of between $5 \%$ and $15 \%$. These rates extrapolated to the respective countries' population would result in several millions more ex smokers each year. [29]

Though there are advertisements projected to help people stop smoking, these may have no personal meaning to the people who smoke i.e., they do not link smoking to any positive family history of non communicable disease. Even if they did and decide to stop, they may not know how to go about stopping the habit. Indirect conditions like anemia may never be related to smoking. The range of benefits of quitting is not known. There is a lack of awareness of pharmacological help to quit smoking. [30]

Simply addressing the topic of smoking is a crucial first step in a medical consultation. Putting smoking on the agenda sends a clear message to the patient that smoking is an important issue. Literature review shows that more positive beliefs and higher confidence level were associated with asking and advising patients to quit. [31]

Physicians have to help each smoker patient realize that he is personally threatened and injured by smoking. Once he accepts this idea, it becomes easier for him to find motivation to quit. A subtle and skillful program of psychological warfare against smoking can be incorporated into medical practice with minimum time and effort and with little and no disruption of work routine. A no nonsense approach is highly effective. To hear nothing or only a weak admonition may validate the wrong message. [32]

Patients with tobacco-related complaints should be told that their problem is related to tobacco use and they should consider quitting. With patients who do not have tobacco related diseases the subject of tobacco usage will have to be addressed in a general way. At this early stage, the health provider might make the point that, after basic needs, like food, clothing, shelter and employment, and freedom from infectious diseases are satisfied, smoking cessation is probably the most important step that can be taken to protect health.

Introducing the smoking topic in the medical curriculum can legitimize and initiate a structured intervention tailored to the patient's needs. The 5A's namely Ask, Assess, Advise, Assist and Arrange can become part of a health professional's routine health care practice. After addressing the issue, patients should be asked and assessed for their smoking habits, advised regarding stopping, assisted to stop and lastly follow up should be arranged. [33]

\section{References}

[1] Report On The Global Tobacco Epidemic 2008, The MPOWER Package, World Health Organization.

[2] K Srinath Reddy, Prakash C Gupta Editors, Report on Tobacco Control in India, Ministry Of Health and Family Welfare, CDC-USA, WHO, 2004.

[3] (IIPS), Mumbai and Ministry of Health and Family welfare, GOI, New Delhi; 2010. 
[4] Jha P, Jacob B, Gajalakshmi V, Gupta PC, Dhingra N, Kumar $\mathrm{R}$, et al. A nationally representative case-control study of smoking and death in India. N Engl J Med. 2008; 358:1137-4.

[5] Tobacco fact sheet, World Health Organization June 2016.

[6] Kishore Chaudhry, Tobacco Control in India,50 Years of Cancer Control in India, SP Agarwal Editor, Ministry Of Health and Family Welfare, Nov 2002.

[7] Encouraging people to stop smoking. Department of Mental health and substance dependence. World Health Organization, 2001 .

[8] Helping Patients stop - The Role of Hospitals in Smoking Cessation. Conference Report, Action on Smoking and Health, Wales, Cardiff, March 2002.

[9] John R Hughes, Motivating and helping smokers to stop smoking. J Gen Intern Med. 2003 Dec; 18(12): 1053-1057.

[10] The World Bank, Smoking prevalence, males (\% of adults), WHO, Global Health Observatory Data Repository.2000.

[11] Glossary of terms used in the Tobacco Atlas, http://www.who.int/tobacco/en/atlas42.pdf.

[12] National Health Interview Survey, National Centre for Health Statistics, CDC 24X 7 saving lives, protecting people. 2009.

[13] Sarasota Demonstration Project, USF Tobacco Strategy Workbook - USF Health, Florida Prevention Research Center. Available

from:http://health.usf.edu/nocms/publichealth/cbpm/tobacco_ workbook.pdf.

[14] M Rani, S Bonu, P Jha, SN Nguyen, L Jamjoum. Tobacco use in India: prevalence and predictors of smoking and chewing in a national cross sectional household survey; Tobacco Control. 2003; 12:e4.

[15] Jindal SK, Aggarwal AN, Chaudhry K, Chhabra SK, D'Souza GA, Gupta D et al; Asthma Epidemiology Study Group. Tobacco smoking in India: prevalence, quit-rates and respiratory morbidity. Indian J Chest Dis Allied Sci. 2006 JanMar; 48 (1):37-42.

[16] A Ghosh. Modification of Kuppuswamy's socioeconomic status scale in context to Nepal: Indian Paediatrics, Vol 46, Dec 17, 2009: 1104-1105.

[17] Current Cigarette Smoking Among Adults in the United States; Centers for Disease Control and Prevention, 2014.

[18] Global Adult Tobacco Survey (GATS), Fact sheet, India 2009-2010.

[19] Cheangaivendan Chezhian, Shruti Murthy, Satish Prasad, Jyoti Bala Kasav, Surapaneni Krishna Mohan, Sangeeta Sharma et al. Exploring Factors that Influence Smoking Initiation and Cessation among Current Smokers J Clin Diagn Res. 2015 May; 9(5): LC08-LC12.
[20] Mythily Subramaniam, Shazana Shahwan, Restria Fauziana, Pratika Satghare, Louisa Picco, Janhavi Ajit Vaingankar et al. Perspectives on Smoking Initiation and Maintenance: A Qualitative Exploration among Singapore Youth, Int. J. Environ. Res. Public Health 2015, 12(8), 8956-8970.

[21] Raj Narain, Sarita Sardana, Sanjay Gupta, Ashok Sehgal. Age at initiation \& prevalence of tobacco use among school children in Noida, India: A cross-sectional questionnaire based survey: Indian J Med Res. 2011 Mar; 133(3): 300-307.

[22] Bhat VM, Cole JW, Sorkin JD, Wozniak MA, Malarcher AM, Giles WH et al. Dose-response relationship between cigarette smoking and risk of ischemic stroke in young women. Stroke. 2008 Sep; 39(9):2439-43.

[23] Smoking, the heart and circulation, Action on smoking health - Fact sheet: The Information Standard, Nov 2013.

[24] Tobacco: totally avoidable risk factor of CVD, World Heart Federation, 2016.

[25] Staying tobacco free, Partnership for a free tobacco Maine, Partnership for a Tobacco-Free Maine, Maine CDC, Maine Department of Health and Human Services, 2016.

[26] Rajmohan Panda, Divya Persai, Sudhir Venkatesan, Missed opportunities for brief intervention in tobacco control in primary care: patients' perspectives from primary health care settings in India: BMC Health Serv Res. 2015; 15: 50.

[27] General Practice and Ethics: Uncertainity and Responsibility, Editors - Christopher Dowrick, Lucy Frith, London, Routledge, 1999.

[28] Raj Kumar, Suraj Prakash, Alka Singh Khushwah, Harsh Kumar, Smoking cessation - control measures, Lung India,2005; 22(2): 68-73.

[29] Allan. V. Prochazka, Edward. J.Boyko, How physicians can help their patients quit smoking- A practical guide, West J Med 1988 Aug; 149: 188-194.

[30] Helping people quit tobacco, A manual for doctors and dentists, WHO, Regional office for South East Asia; 2010.

[31] Abu. S. Abdullah, Frances. A. Stillman et al, Tobacco use and smoking cessation practices among physicians in developing countries: A literature review (1987-2010). Int. J Environ Res Public Health, v 11(1).

[32] Donald T Fredrickson, Helping smokers quit: The Physicians Role. CA: A cancer journal for Physicians, Vol 26, Issue 4, Version of record online; $31 \mathrm{Dec} 2008$.

[33] Toolkit for delivering the 5A's and 5R's brief tobacco interventions to TB patients in primary care, World Health Organization, 2014. 